\title{
RESEARCH
}

\section{Availability of emergency contraception after its deregulation from prescription-only status: a survey of Ontario pharmacies}

\author{
Sheila Dunn MD, Thomas E.R. Brown PharmD, Jason Alldred BSc Pharm
}

\section{ABSTRACT}

In 2005 the emergency contraception formulation of levonorgestrel (Plan B) became available in Ontario pharmacies without a prescription. We surveyed 239 pharmacies 1 month before the regulatory change and $14^{-17}$ months after the change to determine whether availability of the drug increased. The response rates were $79 \%$ and $70 \%$ before and after the change in status. The proportion of pharmacies that had an in-stock supply of Plan B increased from $78 \%$ to $92 \%$ $(p<0.001)$. After the regulatory change, $87 \%$ of the surveyed pharmacies ( $95 \%$ confidence interval $82 \%-92 \%$ ) reported that they had the drug in stock and were willing to dispense it behind the counter. Availability was similar for urban and rural pharmacies, but rural pharmacies had more restricted hours (e.g., $15 \%$ closed on weekends). Thus, as a result of the regulatory change, emergency contraception is more widely available, but access in rural areas is still limited by restricted pharmacy hours.

Une version française de ce résumé est disponible à l'adresse www.cmaj.ca/cgi/content/full/I78/4/423/DCI

CMAJ 2008;178(4):423-4

$\mathrm{E}$ mergency contraception is used to reduce the risk of pregnancy after unprotected intercourse. In April 2005 Health Canada changed the regulatory status of the emergency contraception formulation of levonorgestrel (Plan B) from prescription-only to Schedule II status (behind-the-counter, available from a pharmacist at the patient's request). Although this change eliminates the need to obtain a prescription, access could still be limited by such pharmacy-related factors as lack of stock, store hours, cost and pharmacists' attitudes toward dispensing. Several studies in the United States found that lack of stock was the most common reason for inability to fill a prescription for emergency contraception. ${ }^{1-3}$

We undertook this study to determine whether the regulatory change has been associated with an increase in availability of Plan B in Ontario pharmacies and to examine pharmacy-related barriers to access.

\section{Methods}

We classified all licensed pharmacies as urban or rural and their location as northern or southern. From each of the 4 groups, 60 pharmacies were randomly selected. Because there were only $59 \mathrm{rural} /$ northern pharmacies, all were included in the sample, which left a final sample of 239 pharmacies. Study pharmacies were surveyed twice by telephone. The first survey occurred I month before the regulatory change and the second I4-I7 months after the change. One pharmacist from each pharmacy completed the survey. For some pharmacies the respondent was different for the 2 surveys, and not all pharmacies participated in both surveys.

\section{Results}

Of the 239 pharmacies selected, 188 (79\%) participated in the first survey and $\mathrm{I} 67$ (70\%) in the second survey. The proportion of pharmacies that reported in-stock availability of Plan B increased significantly after the regulatory change, particularly in rural areas (Table I). After the change, $87 \%$ of the surveyed pharmacies (95\% confidence interval [CI] 82\%-92\%) reported that they had the drug in stock as a Schedule II medication, which translated to an estimate of $93 \%$ (95\% CI $86 \%-99 \%$ ) for province-wide availability after weighted analysis to account for sample stratification by location. There were no significant urban-rural differences in reported availability. The proportion of pharmacies that were unwilling to provide Plan B as either a prescription-only or Schedule II drug did not differ significantly before and after the regulatory change ( $5 \%$ and $6 \%$ respectively). When surveyed after the regulatory change, $88 \%$ of the surveyed pharmacies ( $95 \%$ CI $83 \%-93 \%)$ stated that they agreed with the change.

As determined in the second survey, rural pharmacies had more restricted hours of operation: only $24 \%$ were open evenings, as compared with $80 \%$ of urban pharmacies $(p<$ o.0or). Most rural pharmacies (75\%) were closed Sundays,

From the Department of Family and Community Medicine, University of Toronto, and the Women's Health Research Institute (Dunn); the Leslie Dan Faculty of Pharmacy, University of Toronto (Brown, Alldred); and the Department of Pharmacy, Sunnybrook Health Sciences Centre (Brown), Toronto, Ont. 
Table 1: Availability of levonorgestrel emergency contraceptive (Plan B) in Ontario pharmacies before and after the regulatory change from prescription-only to nonprescription status

\begin{tabular}{|c|c|c|c|c|}
\hline \multirow[b]{2}{*}{ Factors affecting availability } & \multicolumn{2}{|c|}{$\begin{array}{l}\text { Time of survey in relation } \\
\text { to regulatory change; } \\
\% \text { of pharmacies }(95 \% \mathrm{Cl})\end{array}$} & \multirow[b]{2}{*}{$\begin{array}{l}\text { Percentage point } \\
\text { change }(95 \% \mathrm{Cl})\end{array}$} & \multirow[b]{2}{*}{$p$ value } \\
\hline & $\begin{array}{c}1 \text { mo before } \\
n=188\end{array}$ & $\begin{array}{c}14-17 \text { mo after } \\
n=167\end{array}$ & & \\
\hline Plan B in stock & 78 & 92 & $14(7$ to 21$)$ & $<0.001$ \\
\hline Urban & 79 & 91 & 12 (2 to 22$)$ & 0.029 \\
\hline Rural & 76 & 93 & 17 (12 to 22$)$ & $<0.002$ \\
\hline $\begin{array}{l}\text { Pharmacist willing to dispense } \\
\text { Plan B (as prescription-only or } \\
\text { as nonprescription drug) }\end{array}$ & 94 & 95 & $1(-4$ to 6$)$ & 0.70 \\
\hline
\end{tabular}

Note: $\mathrm{Cl}=$ confidence interval.

and $15 \%$ were closed weekends. In contrast, only I urban pharmacy was closed both Saturdays and Sundays.

The mean cost of prescription Plan B, as reported by the survey respondents the first survey, was $\$ 27$. Although the second survey asked about cost, few pharmacists provided that information. Some volunteered that they charged a consultation fee in addition to the medication cost.

\section{Interpretation}

Our study revealed that deregulation of Plan B to nonprescription status was associated with a I4 percentage point increase in its in-stock availability in Ontario pharmacies, with over $90 \%$ of the surveyed pharmacies able to provide it as behind-the-counter medication. In-stock availability of Plan B both before and after the regulatory change was much higher than that found in studies in the United States ( $\mathrm{I} \%-45 \%)$, all of which examined availability as a prescription-only product. ${ }^{2-5}$ This may reflect the different status of the drug or greater awareness and acceptance of Plan B in Canada, where national and provincial pharmacy associations have actively promoted its provision by pharmacists.

The survey we conducted after the regulatory change revealed that the pharmacists surveyed strongly support the availability of Plan B as a nonprescription, behind-the-counter drug. This is similar to the attitudes of pharmacists in the United Kingdom, where the drug has been available from pharmacies since 200I. ${ }^{6,7}$ In contrast, studies in the United States, which all preceded deregulation of the drug to nonprescription status, showed mixed attitudes toward pharmacist dispensing of emergency contraceptives, and as many as $84 \%$ of pharmacists surveyed did not support making emergency contraceptives available without a prescription. ${ }^{4,8,9}$ However, the proportion of surveyed pharmacists unwilling to provide Plan B in our study (5\%) is similar to that in US studies. ${ }^{1}$

Women in rural communities face special barriers. Availability of Plan B was similar in the urban and rural pharmacies in our study, but the rural pharmacies had reduced store hours. This finding is similar to that of a 2002 survey in Pennsylvania, although the drug was available in only $32 \%$ of pharmacies in that study. ${ }^{5}$ Although numbers are small, pharmacist refusal or lack of stock in rural pharmacies could severely restrict access.

We could not assess cost as a barrier adequately because pharmacists were reluctant to provide information. Unlike other Schedule II drugs, some pharmacists charged fees for providing Plan B over and above medication costs. This represents a new barrier to access.

The change to nonprescription status of Plan B has been associated with its increased availability in Ontario pharmacies and positive attitudes of pharmacists toward providing it. However, adequate access for women in rural communities requires measures beyond pharmacy availability. The effects of cost and pharmacists' attitudes on access require further study.

This article has been peer reviewed.

Competing interests: None declared for Thomas Brown and Jason Alldred. Sheila Dunn was paid by Paladin Labs, the Canadian distributor of Plan B, as a consultant in relation to a presentation in September 2007 to the National Drug Scheduling Advisory Committee in support of changing the scheduling of this product to Schedule III (on the shelf). This research study and the resulting original manuscript preceded Paladin Labs' request for Dr. Dunn's services.

Contributors: Sheila Dunn and Thomas Brown made substantial contributions to the study concept and design, the analysis and interpretation of the data and the drafting and revision of the manuscript. Jason Alldred acquired the data, contributed to the study design and the interpretation of the data and critically revised the article for important intellectual content. All of the authors approved the final version to be published.

Acknowledgement: This research was supported by a grant from the Ontario Women's Health Council.

\section{REFERENCES}

I. Shacter HE, Gee RE, Long JA. Variation in availability of emergency contraception in pharmacies. Contraception 2007;75:214-7.

2. Espey E, Ogburn T, Howard D, et al. Emergency contraception: pharmacy access in Albuquerque, New Mexico. Obstet Gynecol 2003;I02:918-2I.

3. Bennett W, Petraitis C, D'Anella A, et al. Pharmacists' knowledge and the difficulty of obtaining emergency contraception. Contraception 2003;68:26I-7.

4. Griggs SK, Brown CM. Texas community pharmacists' willingness to participate in pharmacist-initiated emergency contraception. J Am Pharm Assoc (2003) 2007;47:48-57.

5. Chuang CH, Shank LD. Availability of emergency contraception at rural and urban pharmacies in Pennsylvania. Contraception 2006;73:382-5

6. Bissell P, Anderson C. Supplying emergency contraception via community pharmacies in the UK: reflections on the experiences of users and providers. Soc Sci Med 2003;57:2367-78.

7. Blackwell D, Cooper N, Taylor G, et al. Pharmacists' concerns and perceived benefits from the deregulation of hormonal emergency contraception (HEC). Br J Fam Plann I999;25:100-4.

8. Borrego ME, Short J, House N, et al. New Mexico pharmacists' knowledge, attitudes, and beliefs toward prescribing oral emergency contraception. J Am Pharm Assoc (2003) 2006;46:33-43.

9. Hellerstedt WL, Van Riper KK. Emergency contraceptive pills: dispensing practices, knowledge and attitudes of South Dakota pharmacists. Perspect Sex Reprod Health 2005;37:19-24.

Correspondence to: Dr. Sheila Dunn, Family and Community

Medicine, Women's College Hospital, 790 Bay St., 8th floor, Toronto ON M5G IN8; fax 4I6 35I-3727; sheila.dunn@wchospital.ca 